\title{
Cross-sectional study on emergency department management of sepsis
}

\author{
Kevin KC Hung, Rex PK Lam, Ronson SL Lo, Justin W Tenney, Marc LC Yang, Marcus CK Tai, \\ Colin A Graham *
}

\section{A B S T R A C T}

Introduction: Emergency departments (EDs) play an important role in the early identification and management of sepsis. Little is known about local EDs' processes of care for sepsis, adoption of international recommendations, and the impact of the new Sepsis-3 definitions.

Methods: Structured telephone interviews based on the United Kingdom Sepsis Trust 'Exemplar Standards for the Emergency Management of Sepsis' were conducted from January to August 2017 with nominated representatives of all responding public hospital EDs in Hong Kong, followed by a review of hospital/departmental sepsis guidelines by the investigators.

Results: Sixteen of the 18 public EDs in Hong Kong participated in the study. Among various time-critical medical emergencies such as major trauma, sepsis was perceived by the interviewees to be the leading cause of in-hospital mortality and the second most important preventable cause of death. However, only seven EDs reported having departmental guidelines on sepsis care, with four adopting the Quick Sequential Organ Failure Assessment score or its modified versions. All responding EDs reported that antibiotics were stocked within their departments,

This article was published on $14 \mathrm{Nov}$ 2018 at www.hkmj.org. and all EDs with sepsis guidelines mandated early intravenous antibiotic administration within 1 to

optimal sepsis care included lack of knowledge and experience, nursing human resources shortages, and difficulty identifying patients with sepsis in the ED setting.

Conclusion: There are considerable variations in sepsis care among EDs in Hong Kong. More training, resources, and research efforts should be directed to early ED sepsis care, to improve patient outcomes.

\section{Hong Kong Med J 2018;24:571-8 DOI: $10.12809 / \mathrm{hkmj} 177149$ \\ 1,2 KKC Hung, FHKCEM, MPH \\ ${ }^{3}$ RPK Lam, FHKCEM, MPH \\ ${ }^{1}$ RSL Lo, MB, BCh, BAO \\ ${ }^{4}$ JW Tenney, PharmD, BCPS \\ 1,5 MLC Yang, FHKCEM \\ 1,2 MCK Tai, FHKCEM \\ 1,2 CA Graham *, FHKCEM, MD}

Accident and Emergency Medicine Academic Unit, The Chinese University of Hong Kong, Shatin, Hong Kong

${ }^{2}$ Accident and Emergency Department, Prince of Wales Hospital, Shatin, Hong Kong

Emergency Medicine Unit, The University of Hong Kong, Pokfulam, Hong Kong

School of Pharmacy, The Chinese University of Hong Kong, Shatin, Hong Kong

${ }^{5}$ Accident and Emergency Department, Queen Elizabeth Hospital, Jordan, Hong Kong

New knowledge added by this study

- Large variations were found in practice and adoption of international sepsis recommendations across emergency departments (EDs) in Hong Kong. Fewer than half of the EDs had sepsis management guidelines, and there were no regular audits or any registry to monitor the performance of sepsis care.

- Although sepsis was perceived as the leading cause of in-hospital mortality, and second only to trauma in terms of preventable mortality, sepsis has not received a high level of attention within EDs.

- Many EDs specified the requirements for early intravenous antibiotics administration and stocked antibiotics, but they differed in terms of the methods and screening criteria used for identification of patients with sepsis.

Implications for clinical practice or policy

- Sepsis, an emergency condition with high mortality that requires timely intervention, continues to lack adequate attention and resource allocation within EDs in Hong Kong. Now is a critical time to review whether performance indicators for sepsis should be formalised.

- Previous sporadic quality improvement programmes were not adequate to address the high mortality of patients with sepsis who attend EDs. Sustained improvements in resources and training must be provided to improve care for patients with sepsis in Hong Kong.

- By overcoming barriers including the lack of knowledge among ED staff and the need for standard screening to be implemented, EDs in Hong Kong have the capacity to provide a higher standard of care for sepsis patients. 


\section{急症室的膿毒症處理：橫斷面研究}

\section{洪磯正、林沛堅、勞思朗、丁隹斯、楊聿川、戴俊權、簡家廉}

引言：急症室於及早辨識和處理膿毒症 (又稱敗血症) 中發揮重要作 用。然而, 人們對本地急症室的膿毒症護理過程、國際建議的應用, 以至2016年膿毒症第三版國際共識定義的影響所知甚少。

方法：本研究於 2017 年1月至8月期間, 根據英國膿毒症信託基金會發 佈的膿毒症應急管理範例標準, 與香港公立醫院急症室代表進行結構 性電話訪談, 隨後對各間醫院及部門膿毒症指南進行審查。

結果：在香港18間公立醫院急症室中, 共16間參與研究。在各種包括 嚴重創傷等時間緊迫的醫療緊急事件中, 受訪者認為膿毒症是院內死 亡的主因, 也是第二重要的可預防死因。然而, 只有 7 間公立醫院急 症室報告有膿毒症護理的部門指引, 其中4名採用快速序貫器官衰竭 評分 (qSOFA) 或其修訂版。所有回應者均報告有存放抗生素, 而持 有膿毒症指南的急症室均要求檢測後 1 至 2 小時內進行早期抗生素靜脈 注射。缺乏知識和經驗、人力資源短缺, 以及在急症室環境中難以識 別膿毒症患者皆為膿毒症護理的主要障礙。

結論：香港公立醫院急症室的膿毒症處理有頗大差異。建議加強針對 早期急症室膿毒症護理的培訓、資源和研究工作, 以改善治療效果

\section{Introduction}

The global incidence rates of hospital-treated sepsis and severe sepsis have been estimated as 437 and 270 cases per 100000 person years, respectively, ${ }^{1}$ accounting for $17 \%$ and $26 \%$ of hospital mortality, respectively. The same study estimated that 31.5 million cases of sepsis and 19.4 million cases of severe sepsis account for 5.3 million deaths annually worldwide. ${ }^{1}$ The ageing of the population and the increasing number of people living with co-morbid conditions are believed to be important factors associated with the increasing incidence of sepsis. ${ }^{2}$

In early 2016, sepsis was re-defined as 'life-threatening organ dysfunction caused by a dysregulated host response to infection' (Sepsis3). ${ }^{3}$ The criteria used for identifying patients with sepsis were also updated, with the removal of the original systemic inflammatory response syndrome criteria that had been used since the early 1990s. The Sequential Organ Failure Assessment (SOFA) score is commonly used in intensive care units (ICUs) for assessment of organ dysfunction. The quickSOFA (qSOFA) score has been proposed as a bedside screening tool for patients at risk of sepsis with adverse outcomes in emergency departments (EDs) and other non-ICU settings. The evidence base for such a proposal is accumulating, ${ }^{4}$ and the optimal screening tool for sepsis in EDs has not yet been identified. ${ }^{5-8}$

The recent ProCESS, ${ }^{9}$ ProMISE, ${ }^{10}$ and ARISE trials ${ }^{11}$ confirmed the importance of early recognition with fluid resuscitation and appropriate antibiotic therapy in improving sepsis outcomes.
These trials refuted the need for strict adherence to the haemodynamic goals proposed by Rivers et al in 2001 as early goal-directed therapy. ${ }^{2}$ Although it is generally agreed that early initiation of therapy is key to surviving sepsis, controversies remain regarding the initial rate and choice of fluids, the role and choice of inotropes, the identification of infection sources with imaging and other techniques, the use of appropriate antibiotics, and the optimal microbiological workup. ${ }^{13-17}$

The ED occupies a critical position in a patient's journey of sepsis care and plays an important role in the early identification and treatment of sepsis. ${ }^{17}$ Despite frequent encounters with sepsis in EDs, few studies in Hong Kong have investigated sepsis care. Yang et $\mathrm{al}^{18}$ studied patients with sepsis and septic shock in a tertiary university teaching hospital and found no significant change in the in-hospital mortality rate after the implementation of sepsis guidelines (pre-implementation: $29.6 \%$ in 2009; post-implementation: $35.3 \%$ in 2010). Although a significant proportion (25.5\% in 2009 and $40.2 \%$ in 2010) of the recruited patients had hypoperfusion (mean arterial pressure $<65 \mathrm{~mm} \mathrm{Hg}$ or lactate $>4$ $\mathrm{mmol} / \mathrm{L}$ ), only $10.4 \%$ to $11.8 \%$ had blood cultures drawn, $13.0 \%$ to $23.5 \%$ had antibiotics administered, and $24.5 \%$ to $29.6 \%$ had fluid resuscitation initiated in the ED. In that study, sepsis was recognised in the ED in only two-thirds of the patients with sepsis who presented there. Tse et $\mathrm{al}^{19}$ reported similar findings in their study on the impact of departmental sepsis guidelines on mortality (pre-implementation mortality: 25.8\%; post-implementation mortality: $33 \%)$, although there were improved rates of blood culture collection and antibiotic administration in the ED after its implementation. Overall, 17.2\% of patients required direct ICU admission.

Those studies highlighted a few important issues regarding sepsis care in Hong Kong EDs: a heavy burden of sepsis, low compliance with treatment guidelines, and poor patient outcomes despite efforts to standardise care. Evidently, implementing sepsis guidelines is insufficient, and there is a need to evaluate the whole process of care systematically. Moreover, those previous studies involved only individual EDs and, thus, might not be representative of other EDs. Furthermore, the adoption of international recommendations about sepsis care and the impact of the new Sepsis-3 definitions on ED practice are not known. We therefore conducted a survey to evaluate the process of sepsis care, the uptake of international recommendations and the Sepsis-3 definitions to departmental sepsis guidelines, and the barriers faced by health care providers in public EDs in Hong Kong.

\section{Methods}

This was a cross-sectional survey across all EDs in 
Hong Kong in 2017. All 18 public EDs under the Hospital Authority were invited to participate. Private EDs and 24-hour out-patient departments were excluded because $90 \%$ of in-patient care is provided by public hospitals in Hong Kong. One representative was nominated by the Chief of Service (medical director) of each ED to speak on behalf of the department, but not individuals. The telephone survey was based on an interview guide provided before the interview (online supplementary Appendix).

\section{Interview guide development}

The interview guide was developed by the study team with the structure recommended by the UK Sepsis Trust "Exemplar Standards for the Emergency Management of Sepsis". ${ }^{20}$ It included nine domains: departmental guidelines on sepsis, screening criteria for sepsis, physical location and resources, sepsis care and microbiology, antibiotics availability and antimicrobial guidelines, support from ICU and other departments, factors affecting the level of care provided, priority of audits and research, and training and quality assurance.

\section{Telephone interview}

One investigator $(\mathrm{KH})$ performed all of the telephone interviews from January to August 2017. Email invitations were sent to the Chiefs of Services of all 18 departments 2 to 3 weeks before the telephone interviews, and all participating departments were asked to provide their prevailing sepsis guidelines (if available) before the telephone interviews. Departments that had not responded were contacted again up to a total of 4 times.

\section{Data analysis}

All telephone interviews were audio recorded after obtaining consent. Interview data were recorded using a standardised data collection sheet, and data were entered into an Excel spreadsheet. Descriptive statistics were presented as medians for continuous variables (unless specified otherwise) and percentage proportions for categorical variables. Participants ranked each of the nine barriers to sepsis care using a 5-point Likert scale ('not important' 1; 'slightly important' 2; 'important' 3; 'fairy important' 4; and 'very important' 5).

\section{Results}

Out of the 18 EDs, 16 agreed to participate. One department declined to participate, and one did not respond after repeated contacts.

\section{Departmental guidelines on sepsis}

Seven departments reported the presence of sepsis guidelines in their EDs, with three of these departments using the same regional guidelines. Therefore, five different sets of sepsis guidelines were reported to be in current use across all public EDs in Hong Kong. Table 1 shows the characteristics of the EDs with and without sepsis guidelines. Table $2^{3,21-26}$ summarises the core components of the five sets of guidelines reported. Most of the current versions of the guidelines were implemented between 2014 and 2017.

\section{Screening criteria for sepsis}

Four out of the seven departments with sepsis guidelines used qSOFA, which is based on the Sepsis3 recommendations. Three departments (which used the same regional guidelines) used modified qSOFA criteria. The reasons for this, as reported by respondents, included the concern that replacing the definition of 'severe sepsis' with a qSOFA score might increase the number of cases screened as positive. This would result in an increased number of cases requiring management in resuscitation rooms and put further strain on the already scarce ED human resources.

TABLE I. Characteristics of EDs with and without sepsis guidelines

\begin{tabular}{lrrr}
\hline & $\begin{array}{c}\text { Sepsis guidelines in use } \\
(\mathbf{n}=\mathbf{7})\end{array}$ & $\begin{array}{c}\text { Sepsis guidelines not in } \\
\text { use (median, } \mathbf{n = 9})\end{array}$ & $\begin{array}{c}\text { Non-responders (n=2) } \\
\text { ED visits per year }\end{array}$ \\
\hline Hospital beds $^{*}$ & 137416 & 133732 & 133980 \\
\hline ICU beds* & 1650 & 661 & 1196 \\
\hline Daily attendance (2 Sep 2017)† & 20 & 14 & 14 \\
Daily medical admissions (2 Sep 2017) & 268 & 280 & 304 \\
Medical admission (daily medical admissions/daily attendance) & 59 & 54 & 50 \\
\hline
\end{tabular}

Abbreviations: $\mathrm{ED}=$ emergency department; ICU = intensive care unit

* Hospital Authority Statistical Report (2015-2016)

† Public Hospitals Key Statistics issued by Hospital Authority 
TABLE 2. Inclusion criteria and key intervention targets in available guidelines

\begin{tabular}{|c|c|c|c|c|c|c|}
\hline Hospital & & $\mathbf{A}$ & B & C, F, G & D & $\mathbf{E}$ \\
\hline \multirow[t]{3}{*}{ Inclusion criteria } & & $\begin{array}{l}\text { Clinical suspicion of } \\
\text { infection }\end{array}$ & $\begin{array}{l}\text { Clinical suspicion of } \\
\text { infection }\end{array}$ & $\begin{array}{l}\text { Clinical suspicion of } \\
\text { infection }\end{array}$ & $\begin{array}{l}\text { Clinical suspicion of } \\
\text { infection }\end{array}$ & $\begin{array}{l}\text { Clinical diagnosis of } \\
\text { infection }\end{array}$ \\
\hline & $\begin{array}{l}\text { Two or } \\
\text { more of the } \\
\text { following } \\
\text { criteria }\end{array}$ & $\begin{array}{l}\text { - } \text { Temp }>38^{\circ} \mathrm{C} \text { or } \\
<36^{\circ} \mathrm{C} \\
\text { - } \mathrm{HR}>90 \\
\text { - } \mathrm{RR}>20 \\
\text { - } \mathrm{WBC}>12 \text { or } \\
<4 \times 10^{\circ} / \mathrm{L}\end{array}$ & $\begin{array}{l}\text { - } \text { Temp } \geq 38.5^{\circ} \mathrm{C} \text { or } \\
\leq 35.5^{\circ} \mathrm{C} \\
\text { - } \mathrm{HR} \geq 120 \text { or } \leq 50 \\
\text { - } \mathrm{RR} \geq 25 \text { or } \leq 10 \\
\text { - } \mathrm{SpO}<95 \% \\
\text { - Altered LOC or new } \\
\text { onset of confusion }\end{array}$ & NA & $\begin{array}{l}\text { - } \text { Temp }>38^{\circ} \mathrm{C} \text { or } \\
<36^{\circ} \mathrm{C} \\
\text { - } \mathrm{HR}>90 \\
\text { - } \mathrm{RR}>20 \\
\text { - } \mathrm{WBC}>12 \text { or } \\
<4 \times 10^{9} / \mathrm{L} \\
\text { - } \mathrm{BG}>7.7 \mathrm{mmol} / \mathrm{L} \\
\text { in non-diabetic } \\
\text { patients } \\
\text { - Raised CRP } \\
\text { - Acute confusion }\end{array}$ & 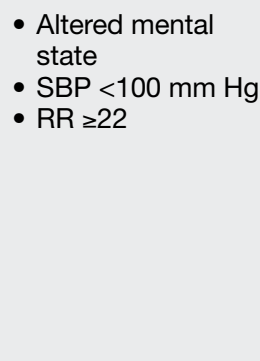 \\
\hline & $\begin{array}{l}\text { One or } \\
\text { more of the } \\
\text { following } \\
\text { criteria }\end{array}$ & $\begin{array}{l}\text { - Hypotension (SBP } \\
<90 \text { or MAP <70) } \\
\text { - Acute lung injury } \\
\text { - Oliguria }(<0.5 \\
\text { mL/kg/hr) } \\
\text { - Creatinine } \\
>177 \mu \mathrm{mol} / \mathrm{L} \\
\text { - Bilirubin }>34 \mu \mathrm{mol} / \mathrm{L} \\
\text { - Platelets }<100 \times \\
109 / \mathrm{L} \\
\text { - INR }>1.5\end{array}$ & $\begin{array}{l}\text { - } \mathrm{SBP}<90 \mathrm{~mm} \mathrm{Hg} \\
\text { - } \mathrm{SBP}>20 \% \\
\text { reduction from } \\
\text { baseline } \\
\text { - Oliguria }(<0.5 \\
\mathrm{mL} / \mathrm{kg} / \mathrm{hr})\end{array}$ & $\begin{array}{l}\text { - Altered mental state } \\
\text { - } \mathrm{SBP}<90 \mathrm{~mm} \mathrm{Hg} \\
\text { - } \mathrm{SpO}_{2}<90 \% \text { on RA, } \\
\text { or } \mathrm{PaO}_{2} / \mathrm{FiO}_{2} \\
<40 \mathrm{kPa}^{2}\end{array}$ & NA & NA \\
\hline \multirow{8}{*}{$\begin{array}{l}\text { Sepsis Six } \\
\text { resuscitation } \\
\text { targets }\end{array}$} & Oxygen & Yes & Yes & Yes & No & No \\
\hline & $\begin{array}{l}\text { Measure } \\
\text { lactate }\end{array}$ & No & Yes (within 3 hours) & Yes & Yes (within 1 hour) & Yes \\
\hline & $\begin{array}{l}\text { Measure } \\
\text { haemoglobin }\end{array}$ & Yes & No & Yes & No & Yes \\
\hline & Blood culture & Yes & Yes & Yes & Yes & Yes \\
\hline & Other cultures & Sputum, urine & Sputum, urine, CSF & Sputum, urine & & Urine \\
\hline & IV antibiotics & Yes, within 1 hour & Yes, within 2 hours & Yes, within 1 hour & Yes, within 1 hour & Yes, within 1 hour \\
\hline & $\begin{array}{l}\text { Adequate fluid } \\
\text { resuscitation }\end{array}$ & $\begin{array}{l}\text { IV crystalloid up to } \\
30 \mathrm{~mL} / \mathrm{kg} / \mathrm{hr}\end{array}$ & $\begin{array}{l}\text { At least } 500 \mathrm{~mL} \\
\text { isotonic crystalloid. } \\
\text { If } \mathrm{SBP}<90 \text {, give } \\
20 \mathrm{~mL} / \mathrm{kg}\end{array}$ & $\begin{array}{l}\text { Normal saline titrate } \\
\text { up to } 30 \mathrm{~mL} / \mathrm{kg}\end{array}$ & & $\begin{array}{l}\text { Normal saline titrate } \\
\text { up to } 30 \mathrm{~mL} / \mathrm{kg}\end{array}$ \\
\hline & $\begin{array}{l}\text { Measure urine } \\
\text { output }\end{array}$ & No & Yes & Yes & No & No \\
\hline $\begin{array}{l}\text { Assessment of } \\
\text { fluid status }\end{array}$ & & Bedside echo & & Bedside USG, CVP & & \\
\hline Vasopressors & & $\begin{array}{l}\text { - Dopamine } \\
\text { - Noradrenaline } \\
\text { - Adrenaline }\end{array}$ & & $\begin{array}{l}\text { - Dopamine } \\
\text { - Adrenaline }\end{array}$ & & $\begin{array}{l}\text { - Dopamine } \\
\text { - Noradrenaline }\end{array}$ \\
\hline \multirow[t]{2}{*}{$\begin{array}{l}\text { Reference } \\
\text { documents }^{3,21-26}\end{array}$} & $\begin{array}{l}\text { Sepsis } \\
\text { management }\end{array}$ & SSC 2012 & $\begin{array}{l}\text { - NHS } \\
\text { - Sepsis Six } \\
\text { - SSC } 2012\end{array}$ & $\begin{array}{l}\text { - SSC } 2012 \\
\text { - Sepsis-3 } 3^{3}\end{array}$ & SSC 2012 & $\begin{array}{l}\text { - SSC } 2016 \\
\text { - Sepsis-3 }\end{array}$ \\
\hline & $\begin{array}{l}\text { Antimicrobial } \\
\text { guide }\end{array}$ & & & $\begin{array}{l}\text { - Local hospital } \\
\text { guide } \\
\text { - Sanford Guide }\end{array}$ & $\begin{array}{l}\text { - IMPACT } \\
\text { - Sanford Guide }\end{array}$ & \\
\hline
\end{tabular}

Abbreviations: $\mathrm{BG}=$ blood glucose; $\mathrm{CRP}=\mathrm{C}$-reactive protein; $\mathrm{CSF}=$ cerebrospinal fluid; $\mathrm{CVP}=$ central venous pressure; $\mathrm{FiO}_{2}=\mathrm{fraction}_{\mathrm{f}}$ of inspired oxygen; HR = heart rate; IMPACT = Interhospital Multidisciplinary Programme on Antimicrobial ChemoTherapy; INR = international normalised ratio; IV = intravenous; LOC = level of consciousness; MAP = mean arterial pressure; NA = not applicable; NHS = National Health Service, Heart of England Sepsis Screening Tool v1.3i 06 I0; $\mathrm{PaO}_{2}=$ partial pressure arterial oxygen; $\mathrm{RA}=$ room air; RR = respiratory rate; Sanford Guide = The Sanford Guide to Antimicrobial Therapy 20 I3; SBP = systolic blood pressure; Sepsis-3 = The Third International Consensus Definitions for Sepsis and Septic Shock; Sepsis Six = Sepsis Six, UK Sepsis Trust; $\mathrm{SpO}_{2}$ = peripheral oxygen saturation; SSC 2012 = Surviving Sepsis Campaign: International Guidelines for Management of Severe Sepsis and Septic Shock 2012; SSC 2016 = Surviving Sepsis Campaign: international guidelines for management of sepsis and septic shock 2016;Temp = temperature; USG = ultrasonogram;WBC = white blood cell 
The use of lactate as a biomarker for clinical decision making in sepsis care was uncommon in the surveyed EDs. Fourteen out of the 16 EDs had access to point-of-care testing of blood gases inside the department, but only five had a lactate module. The ED physicians mainly rely on patients' vital signs and clinical assessment to facilitate recognition of sepsis.

\section{Physical location and resources}

Upon identification of sepsis, two of the EDs' guidelines explicitly mentioned sending the patient to a resuscitation room (or a bed with intensive monitoring, eg, a high-dependency unit). Most of the surveyed EDs (13 of 16) routinely managed patients with sepsis in their resuscitation rooms. None of the EDs had a designated team or a code specifically for patients with sepsis, unlike the management of major trauma, for which the EDs employed a trauma team approach. One of the EDs had designed a sepsis kit consisting of antiseptic swab sticks and pre-set blood collection tubes and had investigation shortcuts in the computer system to facilitate implementation of the guidelines.

\section{Sepsis care and microbiology}

Regarding the resuscitation and stabilisation of patients with sepsis, Table 2 highlights the key areas covered by the existing guidelines. All sets of guidelines refer to the Surviving Sepsis Campaign targets $^{21,22}$ or the UK Sepsis Six targets. ${ }^{23}$ All sets of guidelines also mention time to intravenous antibiotics and microbiological workup, including blood cultures, with the majority specifying intravenous antibiotics within 1 hour of the patient's arrival.

Most EDs (13 of 16) expressed a preference to use normal saline or other isotonic crystalloids for fluid resuscitation. The target volume is up to 20 to $30 \mathrm{~mL} / \mathrm{kg}$, with monitoring of the patient's blood pressure (especially mean arterial pressure) for fluid responsiveness. The use of ultrasonograms was reported to be increasing, especially bedside echocardiograms and inferior vena cava variability, to assess patients' fluid status. Central venous pressure was mentioned, but its use by ED physicians was perceived to be decreasing in frequency. If vasopressors or inotropes were needed, dopamine was the most common choice, as it can be administered via peripheral veins.

Concerning source identification for sepsis, most sets of guidelines (4 of 5) mentioned chest $\mathrm{X}$-rays and urinalysis. If abdominal sepsis was suspected, some EDs would consult their surgical colleagues and make a joint decision as to when a computed tomography (CT) scan or further imaging may be necessary. Individual departments have large variation in access to $\mathrm{CT}$ scans.

\section{Antibiotic availability within the emergency department and antimicrobial guidelines}

All responding EDs reported that antibiotics were stocked in their departments. The numbers of different antibiotics stocked in the EDs ranged from 3 to 18 , with a median of 8.5 . The choice of antibiotics stocked depended on the individual departments' antimicrobial guidelines or regional patterns of pathogen and antibiotic resistance. Both the penicillin and cephalosporin groups were present in all EDs, followed in frequency by fluoroquinolones (14 of 16), others (13 of 16), aminoglycosides (12 of 16), carbapenems (9 of 16), and macrolides (2 of 16).

\section{Support from the intensive care unit and other departments}

Organ failure and septic shock are frequent indications for ICU admission. However, direct ICU admission of patients with single organ failure from EDs is determined by individual ICU admission policy and bed availability. Support from the ICU and in-patient wards varies across different EDs. During the winter surge and flu seasons, access to hospital beds is reduced, causing both ED congestion and compromised sepsis care, especially for those with stable vital signs or poor premorbid conditions. In some of the surveyed hospitals (4 of 16), laboratory and pharmacy support for sepsis care after office hours is limited. This means that those EDs need to dispense drugs or manage patients without the results of certain laboratory investigations.

\section{Training, audit, and research for sepsis}

In terms of training, audits, and research, most of the surveyed EDs (14 of 16) provided ad hoc training on sepsis management to physicians and nurses, but none had a specific sepsis outcome audit or registry. Even though two local studies ${ }^{18,19}$ provided some insight into previous sepsis-related mortality, there has been no agreement regarding standardisation of coding or key performance indicators across different departments.

\section{Factors affecting the level of care provided}

Compared with other time-critical medical emergencies, the respondents perceived sepsis to be the leading cause of in-hospital mortality (average: $4.17)$, followed by acute coronary syndrome (4.09), stroke (3.00), trauma (2.58), and poisoning (1.08). When the respondents were asked which time-critical emergencies had the highest rates of preventable mortality that was not well managed in the ED, trauma was rated the highest (4.00), followed closely by sepsis (3.42), poisoning (2.92), stroke (2.42), and acute coronary syndrome (2.25). The top barriers to optimal sepsis care in EDs identified by the respondents were lack of knowledge and experience 
and inadequate nursing human resources, followed by difficulty identifying patients with sepsis. Table 3 lists all of the barriers investigated by the survey and their perceived importance.

\section{Discussion}

In this study, we found varying levels of adoption of international sepsis guidelines among the responding EDs. Sepsis was perceived to be the top cause of in-hospital mortality and the second leading cause of preventable mortality among all time-critical emergencies. Few EDs had adopted the qSOFA score (which is based on the Sepsis-3 recommendations) in patient screening at 1 year after its publication. Early intravenous antibiotic administration within 1 to 2 hours was mandatory according to all of the surveyed EDs' sepsis guidelines, and all responding EDs reported that antibiotics were stocked within their departments.

Emergency departments across the world have an important responsibility to recognise patients with sepsis, as delays in treatment and administration of antibiotics have been shown to increase inhospital mortality. ${ }^{27}$ All responding public EDs had antibiotics available on-site, but few provided clear guidance on which patients might benefit from timely intravenous antibiotic administration except those with neutropenic or post-chemotherapy fever. The widespread availability of intravenous antibiotics across the EDs is likely a result of the recent Hospital Authority review on acute management of neutropenic fever. All of the participating EDs reported the use of either departmental or clusterwide guidelines for neutropenic fever, and the latest version of the Hospital Authority triage guidelines emphasises the importance of its early recognition and assigns a higher priority to patients with suspected neutropenic fever. ${ }^{28}$ Despite previous studies in Hong Kong that demonstrated high mortality rates among patients with sepsis without neutropenia, ${ }^{18,19}$ sepsis generally does not receive the same level of attention as neutropenia in Hong Kong EDs. To improve patient outcomes, more emphasis should be placed on early resuscitation and antibiotic therapy for sepsis in EDs.

Sustained improvement in sepsis care requires not only guidelines but also more resources and staff training. Further, EDs in Hong Kong face many challenges such as access blockages and overcrowding. ${ }^{29}$ With the rising level of service demand and competing priorities in EDs, it is important to understand the barriers to better sepsis care from health care providers' perspectives. Our study highlights several challenges. The top barriers reported included a lack of knowledge and experience, nursing human resources shortages, and difficulty identifying patients with sepsis. These findings are similar to those of Carlbom and Rubenfeld, ${ }^{30}$ who reported a lack of nursing staff, challenges in the identification of patients with sepsis, and problems with central venous pressure monitoring as barriers to optimal sepsis care. For effective changes to take place, it is necessary to overcome these barriers with more staff training, better nursing human resources provision in EDs, elevation of staff awareness of sepsis, and provision of useful bedside tools for sepsis recognition.

The UK Sepsis Six and quality improvement projects in the UK shed light on how sustained reductions in sepsis mortality can be achieved in a publicly funded health system similar to that of Hong Kong. ${ }^{31}$ In the United States, New York State has required hospitals to follow a sepsis protocol since 2013. Results from 2014 to 2016 showed that $82.5 \%$ of patients across 149 hospitals had the 3 -hour bundle of care (blood cultures, broad-spectrum antibiotics, and lactate measurement) completed

TABLE 3. Barriers to optimal care for patients with sepsis perceived by the respondents

\begin{tabular}{|c|c|c|c|c|c|}
\hline & Not important & $\begin{array}{l}\text { Slightly } \\
\text { important }\end{array}$ & Important & $\begin{array}{l}\text { Fairly } \\
\text { important }\end{array}$ & Very important \\
\hline $\begin{array}{l}\text { Knowledge about and experience in managing patients } \\
\text { with sepsis }\end{array}$ & 0 & $8.3 \%$ & $25 \%$ & $41.7 \%$ & $25 \%$ \\
\hline Nursing human resources required & $8.3 \%$ & $16.7 \%$ & $8.3 \%$ & $16.7 \%$ & $50 \%$ \\
\hline Identifying patients with sepsis & 0 & $16.7 \%$ & $25 \%$ & $25 \%$ & $33.3 \%$ \\
\hline Doctors' workload & $16.7 \%$ & 0 & $25 \%$ & $16.7 \%$ & $41.7 \%$ \\
\hline Equipment/drugs available & $8.3 \%$ & $16.7 \%$ & $8.3 \%$ & $41.7 \%$ & $25 \%$ \\
\hline Lack of agreement about optimal care pathway & $8.3 \%$ & 0 & $41.7 \%$ & $33.3 \%$ & $16.7 \%$ \\
\hline Handover to ICU or colleagues from other specialties & $16.7 \%$ & $25 \%$ & $25 \%$ & $25 \%$ & $8.3 \%$ \\
\hline Vacancy or number of resuscitation rooms/monitored beds & $25 \%$ & $8.3 \%$ & $66.7 \%$ & 0 & 0 \\
\hline Skills for CVP/central line insertion & $16.7 \%$ & $66.7 \%$ & $16.7 \%$ & 0 & 0 \\
\hline
\end{tabular}

Abbreviations: CVP = central venous pressure; ICU = intensive care unit 
within 3 hours, with a median time to completion of 1.3 hours. $^{32}$

Steady improvements in survival of other time-critical emergencies including ST elevation myocardial infarction, ${ }^{33}$ acute ischemic stroke, ${ }^{34}$ and major trauma ${ }^{35}$ have been achieved in Hong Kong through systemic changes, more staff training and resources, multidisciplinary collaboration, and regular interdepartmental audits. Regular and systematic data collection from EDs in Hong Kong for monitoring, evaluation of performance and processes of care, and benchmarking is important to assess the impact of various ED sepsis initiatives.

\section{Limitations}

This study has a number of limitations. Not all public EDs in Hong Kong participated in the study. However, we believe that our findings are representative of the current ED processes of sepsis care in Hong Kong. We did not include other private EDs, which might affect the generalisability of our findings; however, ambulances in Hong Kong bring patients to public EDs only, and 90\% of all in-patient care is provided by public hospitals. We have likely covered the majority of the EDs in Hong Kong that provide emergency care to patients with sepsis, especially those in critical condition.

Second, it is possible that some respondents might have expressed personal bias when responding to the questions, especially those regarding the barriers to optimal sepsis care. This could have affected the results despite the fact that respondents were reminded that their replies should provide the views of the department (not their personal points of view), and even though the interview guide was shared in advance to consolidate departmental opinions. Individual questionnaires targeting various seniority levels of ED staff might be better to address these questions in the future.

Finally, we relied heavily on the materials provided by the respondents, and their views do not necessarily reflect real clinical practice. However, this provides a beginning to facilitate a better systematic understanding of sepsis care in Hong Kong EDs as a whole. Future studies are warranted to evaluate actual clinical practice, patient outcomes in cases of sepsis, and the impact of adopting new sepsis definitions and international guidelines on a territory-wide basis.

\section{Conclusion}

Compared with other time-critical emergencies with high mortality and impact on patients, sepsis has not received adequate attention in Hong Kong EDs. The process of care varies considerably among EDs, and few have departmental sepsis guidelines. With increasing recognition of the burden of sepsis among Hong Kong EDs, more training and resources for management of these patients and the establishment of formal performance indicators should be considered. Systematic routine data collection for prospective multicentre research is needed to improve patient care.

\section{Author contributions}

Concept and design: KKC Hung, RPK Lam, RSL Lo, CA Graham.

Acquisition of data: KKC Hung, RPK Lam, MLC Yang, MCK Tai.

Analysis and interpretation of data: KKC Hung, JW Tenney. Drafting of the article: KKC Hung, RPK Lam.

Critical revision for important intellectual content: All authors.

\section{Acknowledgement}

We thank all of the participants for their time and support of this study.

\section{Declaration}

All authors have disclosed no conflicts of interest. All authors had full access to the data, contributed to the study, approved the final version for publication, and take responsibility for its accuracy and integrity.

\section{Funding/support}

This research received no specific grant from any funding agency in the public, commercial, or not-for-profit sectors.

\section{Ethical approval}

Ethical approval was obtained from the Survey and Behavioural Research Ethics Committee of the Chinese University of Hong Kong (097-16). Verbal informed consent was obtained from the participants.

\section{References}

1. Fleischmann C, Scherag A, Adhikari NK, et al. Assessment of global incidence and mortality of hospital-treated sepsis. Current estimates and limitations. Am J Respir Crit Care Med 2016;193:259-72.

2. Kempker JA, Martin GS. The changing epidemiology and definitions of sepsis. Clin Chest Med 2016;37:165-79.

3. Singer M, Deutschman CS, Seymour CW, et al. The Third International Consensus Definitions for Sepsis and Septic Shock (Sepsis-3). JAMA 2016;315:801-10.

4. Churpek MM, Snyder A, Han X, et al. Quick sepsis-related organ failure assessment, systemic inflammatory response syndrome, and early warning scores for detecting clinical deterioration in infected patients outside the intensive care unit. Am J Respir Crit Care Med 2017;195:906-11.

5. Lo RS, Brabrand M, Kurland L, Graham CA. Sepsiswhere are the emergency physicians? Eur J Emerg Med 2016;23:159.

6. Kaukonen KM, Bailey M, Pilcher D, Cooper DJ, Bellomo R. Systemic inflammatory response syndrome criteria in defining severe sepsis. N Engl J Med 2015;372:1629-38.

7. Vincent JL, Martin GS, Levy MM. qSOFA does not replace SIRS in the definition of sepsis. Crit Care 2016;20:210.

8. Macdonald SP, Arendts G, Fatovich DM, Brown SG. 
Comparison of PIRO, SOFA, and MEDS scores for predicting mortality in emergency department patients with severe sepsis and septic shock. Acad Emerg Med 2014;21:1257-63.

9. ProCESS Investigators, Yealy DM, Kellum JA, et al. A randomized trial of protocol-based care for early septic shock. N Engl J Med 2014;370:1683-93.

10. Mouncey PR, Osborn TM, Power GS, et al. Trial of early, goal-directed resuscitation for septic shock. N Engl J Med 2015;372:1301-11.

11. ARISE Investigators, ANZICS Clinical Trials Group, Peake SL, et al. Goal-directed resuscitation for patients with early septic shock. N Engl J Med 2014;371:1496-506.

12. Rivers E, Nguyen B, Havstad S, et al. Early goal-directed therapy in the treatment of severe sepsis and septic shock. N Engl J Med 2001;345:1368-77.

13. Gotts JE, Matthay MA. Sepsis: pathophysiology and clinical management. BMJ 2016;353:i1585.

14. Cohen J, Vincent JL, Adhikari NK, et al. Sepsis: a roadmap for future research. Lancet infect Dis 2015;15:581-614.

15. Andrews B, Semler MW, Muchemwa L, et al. Effect of an early resuscitation protocol on in-hospital mortality among adults with sepsis and hypotension: a randomized clinical trial. JAMA 2017;318:1233-40.

16. McIntyre L, Rowe BH, Walsh TS, et al. Multicountry survey of emergency and critical care medicine physicians' fluid resuscitation practices for adult patients with early septic shock. BMJ Open 2016;6:e010041.

17. Lam SM, Lau AC, Lam RP, Yan WW. Clinical management of sepsis. Hong Kong Med J 2017;23:296.

18. Yang ML, Graham CA, Rainer TH. Outcome after implementation of sepsis guideline in the emergency department of a university hospital in Hong Kong. Hong Kong J Emerg Med 2015;22:163-71.

19. Tse CL, Lui CT, Wong CY, Ong KL, Fung HT, Tang SY. Impact of a sepsis guideline in emergency department on outcome of patients with severe sepsis. Hong Kong J Emerg Med 2017;24:123-31.

20. Nutbeam T, Daniels R, Keep J; for the UK Sepsis Trust. Toolkit: emergency department management of sepsis in adults and young people over 12 years-2016. Available from: https://sepsistrust.org/wp-content/ uploads/2018/06/ED-toolkit-2016-Final-1.pdf. Accessed 4 May 2018.

21. Dellinger RP, Levy MM, Rhodes A, et al. Surviving Sepsis Campaign: International Guidelines for Management of Severe Sepsis and Septic Shock, 2012. Intensive Care Med 2013;39:165-228.

22. National Health Service UK. Sepsis guidance implementation advice for adults. Available from: https:// www.england.nhs.uk/wp-content/uploads/2017/09/ sepsis-guidance-implementation-advice-for-adults.pdf. Accessed 3 Nov 2018.

23. Daniels R, Nutbeam T, McNamara G, Galvin C. The sepsis six and the severe sepsis resuscitation bundle: a prospective observational cohort study. Emerg Med J 2011;28:507-12.

24. Gilbert DN, Moellering RC, Eliopoulos GM, Chambers HF, Saag MS. The Sanford Guide to Antimicrobial Therapy. 42nd ed. Antimicrobial Therapy Inc; 2012.

25. Ho PL, Wong SS. Reducing bacterial resistance with IMPACT-Interhospital Multi-disciplinary Programme on Antimicrobial ChemoTherapy. Hong Kong: Centre for Health Protection; 2012.

26. Rhodes A, Evans LE, Alhazzani W, et al. Surviving Sepsis Campaign: International Guidelines for Management of Sepsis and Septic Shock: 2016. Intensive Care Med 2017;43:304-77.

27. Seymour CW, Kahn JM, Martin-Gill C, et al. Delays from first medical contact to antibiotic administration for sepsis. Crit Care Med 2017;45:759-65.

28. A\&E Triage Guidelines version 5. Hong Kong: Hospital Authority; 2016.

29. Chan SS, Cheung NK, Graham CA, Rainer TH. Strategies and solutions to alleviate access block and overcrowding in emergency departments. Hong Kong Med J 2015;21:34552 .

30. Carlbom DJ, Rubenfeld GD. Barriers to implementing protocol-based sepsis resuscitation in the emergency department-results of a national survey. Crit Care Med 2007;35:2525-32.

31. Bentley J, Henderson S, Thakore S, Donald M, Wang W. Seeking sepsis in the emergency department-identifying barriers to delivery of the Sepsis 6. BMJ Qual Improv Rep 2016;5:u206760.w3983.

32. Seymour CW, Gesten F, Prescott HC, et al. Time to treatment and mortality during mandated emergency care for sepsis. N Engl J Med 2017;376:2235-44.

33. Cheung GS, Tsui KL, Lau CC, et al. Primary percutaneous coronary intervention for ST elevation myocardial infarction: performance with focus on timeliness of treatment. Hong Kong Med J 2010;16:347-53.

34. Wong $\mathrm{EH}$, Yu SC, Lau AY, et al. Intra-arterial revascularisation therapy for acute ischaemic stroke: initial experience in a Hong Kong hospital. Hong Kong Med J 2013;19:135-41.

35. Cheung NK, Yeung JH, Chan JT, Cameron PA, Graham CA, Rainer TH. Primary trauma diversion: initial experience in Hong Kong. J Trauma 2006;61:954-60. 